\title{
Three-Dimensional Concentration Mapping of Gases using a Portable Mass Spectrometer System
}

\author{
Timothy P. Griffin, ${ }^{\text {a Jorge Andres Diaz, }}{ }^{\mathrm{b}} \mathrm{C}$ Richard Arkin, ${ }^{\mathrm{c}}$ \\ Carlomagno Soto, ${ }^{\mathrm{d}}$ Charles H. Curley, ${ }^{\mathrm{c}}$ and Oliver Gomez ${ }^{\mathrm{d}}$ \\ a NASA, NE-L2, Kennedy Space Center, Florida, USA \\ ${ }^{b}$ CICANUM, Physics School, Universidad de Costa Rica, San Jose, Costa Rica \\ ${ }^{c}$ ASRC Aerospace Corporation, ASRC-14, Kennedy Space Center, Florida, USA \\ d National Program for Airborne Research, PRIAS-CENAT, San Jose, Costa Rica
}

\begin{abstract}
The visualization of hazardous gaseous emissions at volcanoes using in-situ mass spectrometry (MS) is a key step towards a better comprehension of the geophysical phenomena surrounding eruptive activity. In-situ data consisting of helium, carbon dioxide, sulfur dioxide, and other gas species, were acquired with a quadrupole based MS system. Global position systems (GPS) and MS data were plotted on ground imagery, topography, and remote sensing data collected by a host of instruments during the second Costa Rica Airborne Research and Technology Applications (CARTA) mission. This combination of gas and imaging data allowed three-dimensional (3D) visualization of the volcanic plume and the mapping of gas concentration at several volcanic structures and urban areas. This combined set of data has demonstrated a better tool to assess hazardous conditions by visualizing and modeling of possible scenarios of volcanic activity. The MS system is used for in-situ measurement of $3 \mathrm{D}$ gas concentrations at different volcanic locations with three different transportation platforms: aircraft, auto, and hand-carried. The demonstration for urban contamination mapping is also presented as another possible use for the MS system. (J Am Soc Mass Spectrom 2008, 19, 1411-1418) (C 2008 American Society for Mass Spectrometry
\end{abstract}

$\mathrm{T}$ There has been an increased need for the direct measurements of volcanic gas emissions to gain a better understanding of the precursor signals of an eruption. There is also a better appreciation of the hazards that gaseous emissions from volcanic sites pose to their immediate surroundings as well as their effects to the atmosphere on a global level. The mapping and visualization of these hazardous gases using in-situ MS is a key step towards a better comprehension of the geophysical phenomena under study, and the direct application of the advances of integrated MS technology to prevent the loss of life.

To assess major potential volcanic events, it is important to monitor day to day volcanic activity. This can be accomplished by detecting the emission of gases into the atmosphere in conjunction with other more established techniques such as the measurement of seismic events and magnetometry [1]. A common volcanic event is the release of toxic gases in the region near the crater, which not only affects human health but disrupts agricultural and commercial activity [2]. In the case of San Jose, the capital of Costa Rica, it is surrounded by

Address reprint requests to Dr. T. P. Griffin, NASA, NE-L2, Kennedy Space Center, FL 32815-0087, USA. E-mail: Timothy.P.Griffin@NASA.gov three active volcanoes: Poas, Irazu, and Turrialba, along with the dormant volcano of Barba, making it vulnerable to any increase of volcanic activity at these volcanoes.

The most abundant gases released by active volcanoes, in order of decreasing concentration, are water vapor, carbon dioxide, sulfur dioxide, and hydrogen sulfide. In lesser amounts, volcanoes also release helium, hydrogen, hydrochloric acid, hydrofluoric acid, methane, and carbon monoxide [3-5]. Most gases are formed in the mantle by chemical reactions involving very hot minerals in combination with water and oxygen. Helium is formed beneath the earth's surface as a by-product of radioactive decay from heavier elements, and is physically trapped until released by new volcanic activity [6]. Helium escapes rapidly into the atmosphere, making its steady-state concentration in air extremely low. Therefore, increased helium emissions indicate gas being released directly from the magmatic chamber through the formation of new crustal fissures, indicating changes in volcanic activity and a possible catastrophic event. Many gases emitted by volcanoes are hazardous for the surrounding environment, such as sulfur dioxide, hydrochloric acid, hydrogen sulfide, and carbon dioxide when emitted in large concentrations. These effects have been observed during recent 
visits to Turrialba volcano where vegetation down wind of the crater and at the summit has been killed in just a few months. The vegetation decimation has been caused by the emission of gases such as $\mathrm{SO}_{2}$ interacting with the low clouds surrounding the volcano forming sulfuric acid and causing acid rain. Also, high $\mathrm{CO}_{2}$ flux has contributed to the vegetation kill around the summit of Turrialba volcano. The emitted gases, such as sulfuric acid, hydrochloric acid, and hydrogen sulfide, not only affect local vegetation but can have a wider impact on crop yields. In addition to the impact on vegetation, gas emissions have wide ranging effects, including respiratory stress to humans and other organisms as well as global climate impact through the release of large quantities of sulfur dioxide into the stratosphere in large eruptions [7].

There are many ways to measure gaseous emissions, such as IR, GC, electrochemical sensors, and optical sensors [8]. MS offers a number of advantages over these techniques, including the determination of multiple chemical species, a large dynamic range, high sensitivity, and high selectivity. Also, MS is the only analytical technique capable of monitoring in-situ helium concentrations in real time [9]. Additionally, MS is capable of measuring isotope ratios. Isotope analysis can be used to identify distinct magmatic processes for different conditions of pressure, temperature, and bulk composition [10]. The system discussed here was previously used to investigate changes in oxygen-32 to oxygen-34 ratios with altitude changes [11].

The usefulness of in-situ MS for volcanic applications has been previously demonstrated by the researchers through a series of campaigns into Hawaii and Costa Rican volcanoes [9, 12]. Using portable mass spectrometers to characterize volcanoes is extremely beneficial. The grab bottle with post-deployment analysis is the most common sampling method in use today [8]. The greatest drawback of this method is the limited number of samples that can be taken during a single deployment. This method has very limited spatial and temporal resolution. It also restricts the spatial range that can be characterized. A portable gas analysis instrument allows a near infinite number of samples to be analyzed with excellent spatial range and resolution. MS was chosen for several reasons. With a typical analysis time of $1 \mathrm{~s}$, MS is superior to chromatographic techniques, thus providing excellent temporal resolution. And with the ability to measure complex samples in varied matrices, MS is superior to most optical techniques. Also, MS is the prime choice for helium analysis, which has been shown to be an indicator of volcanic activity [13].

Since the current state-of-the-art in gas monitoring $[14,15]$ failed to meet the requirements for this application, research collaboration was established between personnel at NASA Kennedy Space Center and scientists in Costa Rica. While NASA was primarily interested in advancing monitoring technology, the University of Costa Rica was interested in providing a better tool for the assessment of volcanic gas emissions and their agricultural, economic, and health impacts on Costa Rica. As detailed in a previous publication [11], KSC developed and demonstrated a portable flightcapable mass spectrometer system to monitor atmospheric gases from sea level to 44,000 feet a.m.s.l. ( 13.4 $\mathrm{km}$ ). The system was designed to be operated either fully autonomously, including calibrations, or with operator inputs. The data can be displayed in real-time via a laptop computer and archived for later processing. A revised version of the system was deployed for the second CARTA field campaign and transported to Costa Rica to monitor atmospheric gases in and around volcanoes, as well as in populated areas. The system was flown through volcanic plumes aboard multiple aircraft, carried by hand into the crater of volcanoes, and driven around the city of San Jose, where it successfully monitored gases of interest. The project demonstrated the capabilities of the instrument for the application, providing useful data and instrumentation to help resolve key problems.

The present article describes the use of an MS system to detect in-situ gas concentrations both at the fumaroles site and in the gas layers surrounding the volcano using different transportation platforms. This system can also be used to provide ground truth data for remote sensing techniques, including airborne and satellite based measurements. The long-term objective is to have small autonomous mass spectrometers capable of continuous or on-demand gas monitoring to assess volcanic activity. Such systems could be located in ground stations for long-term characterization and, when volcanic activity prevents direct access, three-dimensional (3D) chemical data of the plume using airborne platforms could provide near-real time assessment.

\section{Experimental/Methods}

The mass spectrometer system was taken into the field in Costa Rica by multiple methods. These methods included aircraft, hand-carried, and automobile transport.

\section{Instrument}

The aircraft-based volcanic emissions mass spectrometer (AVEMS) used for this research has been described in detail previously [11]. Briefly, the mass spectrometer consisted of the Stanford Research Systems (SRS) quadrupole MS RGA 200, Alcatel 30+ turbo pump, and two KNF 84.4 diaphragm pumps. A turbo pump was utilized for its ability to operate in high oxygen and water environments along with the need to monitor potentially high levels of helium. The instrument incorporated an autonomous calibration subsystem to provide accurate concentration data on-site. Calibration was achieved with three in-system NIST traceable (tertiary standards) calibration bottles and pressure control at the direct inlet to the vacuum chamber. Calibration was 


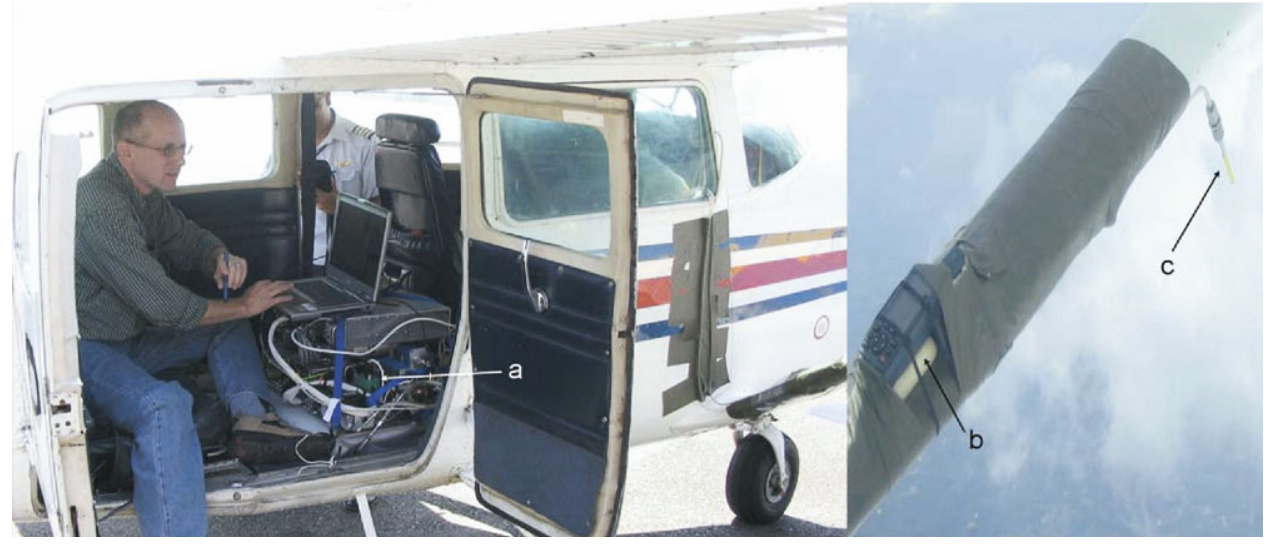

Figure 1. This Cessna SOLOY 206 was one of two aircraft used to collect gas concentration profiles. The mass spectrometer system (a) was installed in the middle row of seats; the GPS (b) and sample intake (c) were mounted on the starboard strut.

performed either when the operator requested or automatically when the sample pressure varied beyond preset operating parameters. Each calibration cycle required 10 to $15 \mathrm{~min}$ to complete and utilized a twopoint calibration curve with an additional point for calibration verification. The mass analyzer was operated in single ion monitoring mode and the species monitored varied by deployment, but the typical configuration was to monitor helium, water, carbon diox- ide, and sulfur dioxide; with mass-to-charge ratios of 4 , 18,44 , and 64 , respectively. The calibration bottles used here contained all of these compounds except water. Surface effects with pressurized gas bottles and the vacuum chamber make calibration of water unreliable. As a result, water data here were provided in terms of sensor response (picoamps). Flow rate, which affects sample transport time, was measured with the pressure control system. For all data shown here, power was
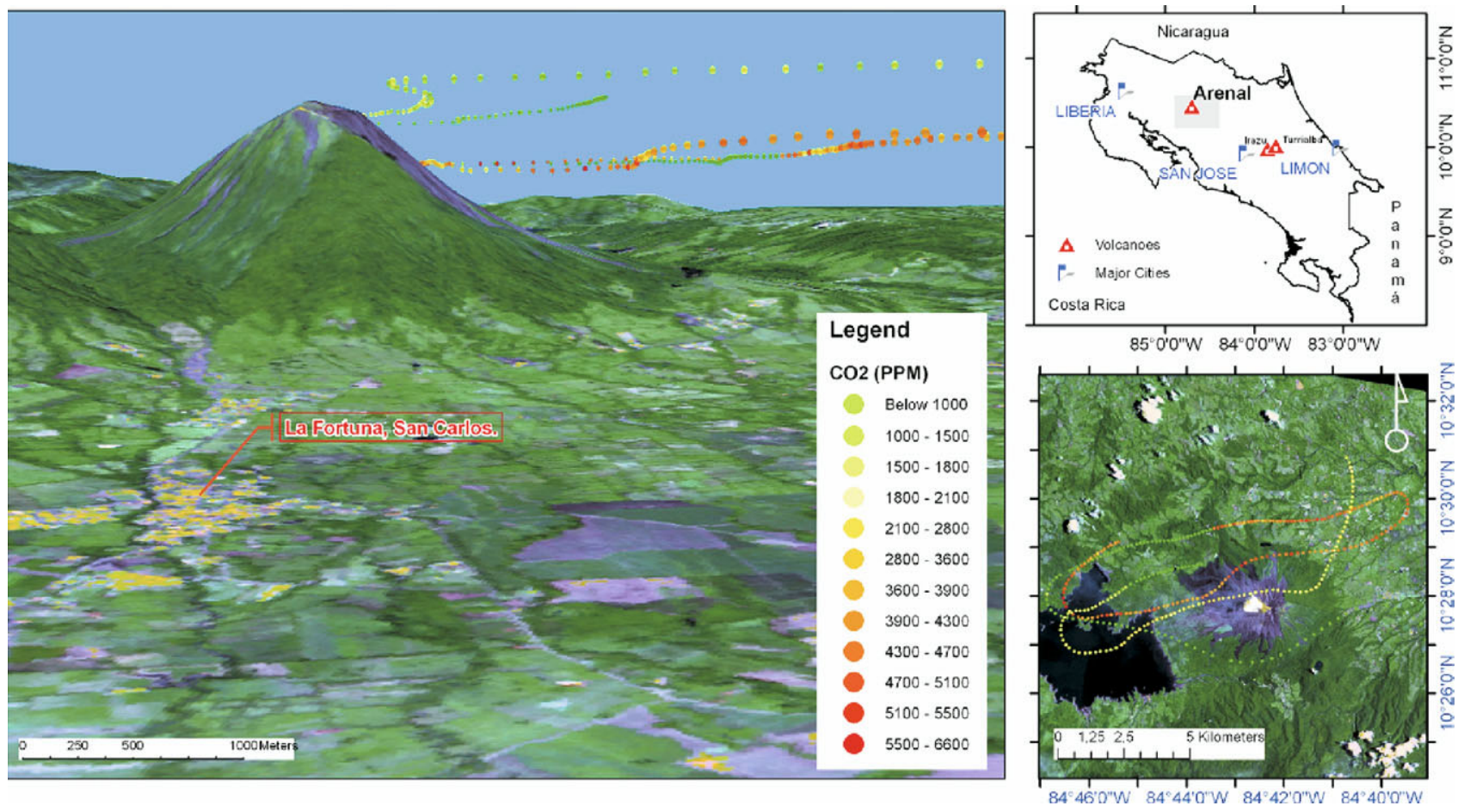

Figure 2. Shown is the $3 \mathrm{D}$ concentration profile of the plume around Arenal Volcano (caldera elevation 5380 feet, $1640 \mathrm{~m}$ ). Plume data were taken at altitudes varying from $1000 \mathrm{~m}$ to $2000 \mathrm{~m}$ downwind from the active crater. High $\mathrm{CO}_{2}$ concentrations are present at lower altitude, which coincides with an inversion layer present near the top of the volcano. It is interesting to observe that low concentrations are present above the crater, sending the high concentration plume closer to the ground, thus maximizing the hazardous impact to small towns and villages down wind from the crater. 
provided by two $24 \mathrm{~V}$ batteries, with two hot-swappable spares available for additional run time $(\sim 3 \mathrm{~h}$ run time per battery). A Magellan model 315 Global Positioning System (GPS) unit (Magellan, Santa Clara, CA) was connected to the mass spectrometer system via RS-232, which provided latitude, longitude, altitude, and coordinated universal time (UTC). Although capable of fully autonomous operation, instrument control and data acquisition were performed interactively for the presented data. During these missions, the system was operated directly by laptop computer. All data were automatically integrated into a single computer file by in-house software, resulting in synchronized GPS and chemical information.

\section{Aircraft Deployment}

Flights were performed around all major volcanoes in Costa Rica: Arenal, Irazu, Miravalles, Poas, Rincon de la Vieja, and Turrialba. Only a limited, yet representative, dataset is presented here from flights around Arenal, Irazu, and Turrialba volcanoes.

Although a Piper Navajo was also used for some flights, a Cessna Soloy 206 was used for the presented data. The different flights ranged from $30 \mathrm{~min}$ to $2 \mathrm{~h}$ in duration, flying up to an altitude of 15,000 feet a.m.s.l. $(\sim 4.6 \mathrm{~km})$. With a scan rate of $3 \mathrm{~s} / \mathrm{scan}$ and an aircraft speed between 275 and $375 \mathrm{~km} / \mathrm{h}$, the MS gas data spatial resolution varied from 230 to $320 \mathrm{~m}$, which is five times better spatial resolution than the previous CARTA Mission flown with NASA's WB-57 aircraft.
The MS system, batteries, and computer were strapped into the plane (Figure 1). To ensure that the engine exhaust was not detected during flight, the sample line ran to the starboard wing strut on the Cessna. The sample intake extended out from the skin of the aircraft $\sim 6^{\prime \prime}(15 \mathrm{~cm})$ to minimize slip stream effects. The GPS was attached on the same strut near the sample intake.

\section{Hand-Carried Deployment}

The system was hand-carried into the crater of Turrialba and Miravalles volcanoes. During operation, the instrument was placed in a stationary position and sampling was done by moving a 50-foot $(15 \mathrm{~m})$ Tygon sample line in a raster motion. The instrument was then repositioned and sample collection continued. This position-raster-position operation was performed several times to collect data in the area of interest. The GPS was attached to the end of the sample line so that mapping of the sampling location would be possible. The sample site included several visible fumaroles.

\section{Automobile Deployment}

For monitoring of municipal pollution levels and to detect background levels of hazardous gases at the city before any major volcanic activity, the instrument was placed in the back compartment of a sport utility vehicle. In an effort to keep from sampling the vehicle's own exhaust, the sample intake line was routed through the vehicle window and attached to the lug-
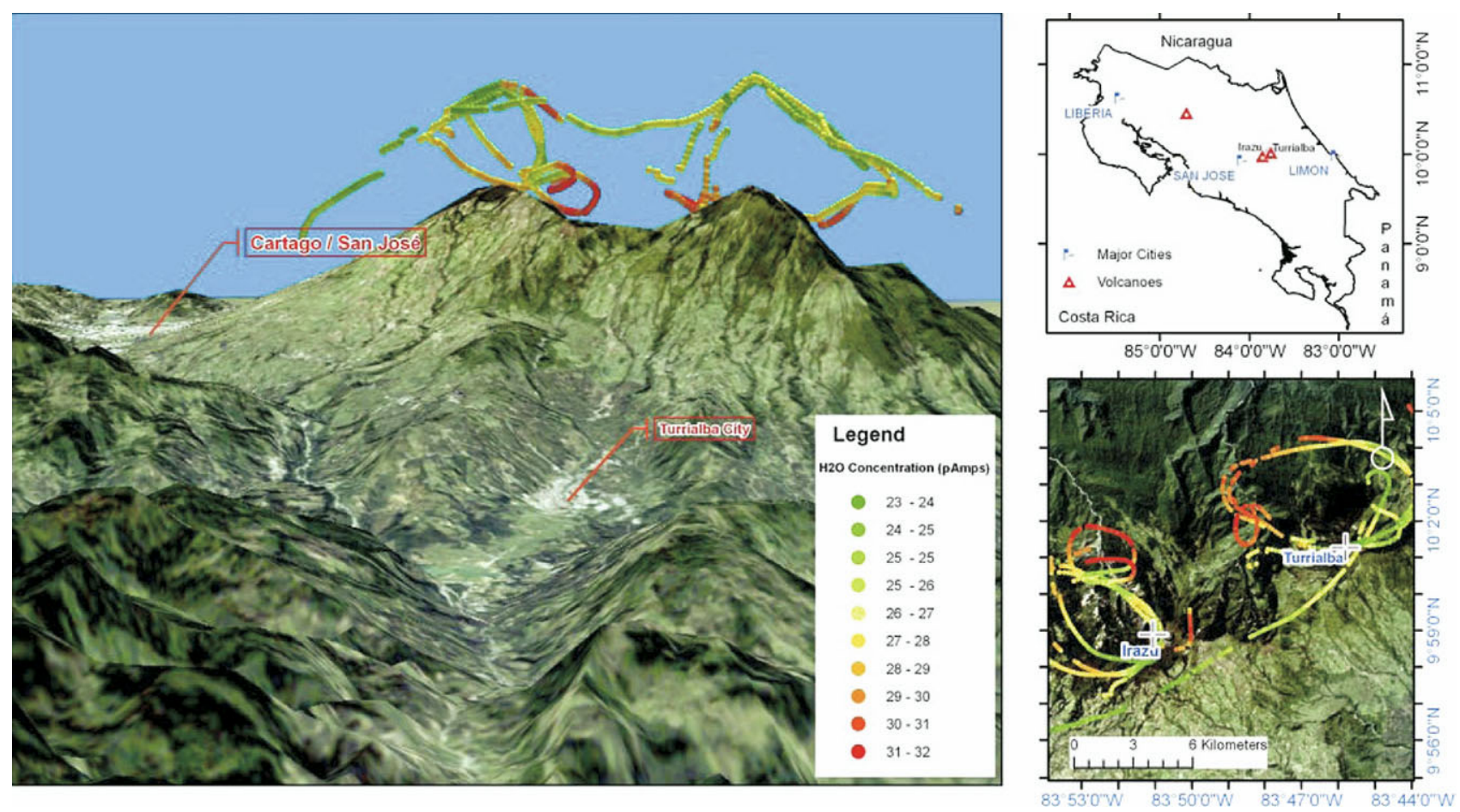

Figure 3. Water signal (in arbitrary response units, pAmps) around Irazu and Turrialba. Note that the higher concentration (red) is at lower altitude than the caldera and follows the valley between the two volcanoes. 
gage rack above the front passenger side door with the intake facing forward.

\section{Data Analysis}

The measured data had to be correlated to the correct GPS coordinates and time. This correlation was needed because the sample transport time, the time it took for the sample to travel from the sampling location to the mass spectrometer, along with the speed of the aircraft, would have caused errors when plotting the data. To establish instrument response time, a test was performed before each deployment to establish the time lag between introduction of the sample at the inlet and an increase in the MS signal.

Three-dimensional concentration mapping was obtained by integrating several sets of data. First, images were obtained using aerial photography from the same CARTA mission acquired using a Leica RC-30 mapping camera (Leica Geosystems, St. Gallen, Switzerland) and an infrared digital camera system (Cirrus Digital Systems, Belvedere Tiburon, CA) or using multispectral advanced spaceborne thermal emission and reflection radiometer (ASTER), TERRA Satellite, JPL-NASA satellite images. Topography data used were either from the airborne synthetic aperture radar (AIRSAR) 2004 Mesoamerica mission (JPL-NASA) mission and SRTM (Shuttle Radar Topographic Mapping Mission) data [16] as well as digitalized 1:40,000 toposheet (Instituto Geográ- fico Nacional, Ministerio de Obras Publicas y Transportes, Costa Rica). Each image was geo-referenced based on known ground truth control points providing a twodimensional (2D) view of the mapping area. The elevation then was added using the topographic dataset and visualized using the ArcGlobe module for ArcGIS 9.0 software (ESRI, Redlands, CA) generating a 3D rendering of the scene. Each gas concentration point was tagged with the corrected onboard GPS data, which provided geo-referencing to the MS data, and was then displayed over the 3D scene. This multilayer integration provided a 3D visualization to map the gas concentration, assess gas emission dynamics, and provide a tool to assess hazardous conditions in the monitored area.

\section{Results and Discussion}

The data obtained by the different transportation techniques were examined and plotted. From the results, it was possible to detect areas of higher concentration and thus determine regions of concern around volcanoes and cities. From the data gathered, a few representative examples of 3D mass spectrometer gas concentration mapping are now presented.

\section{Aircraft Deployment}

The $\mathrm{CO}_{2}$ data obtained while flying around Arenal volcano are shown in Figure 2. The red data points

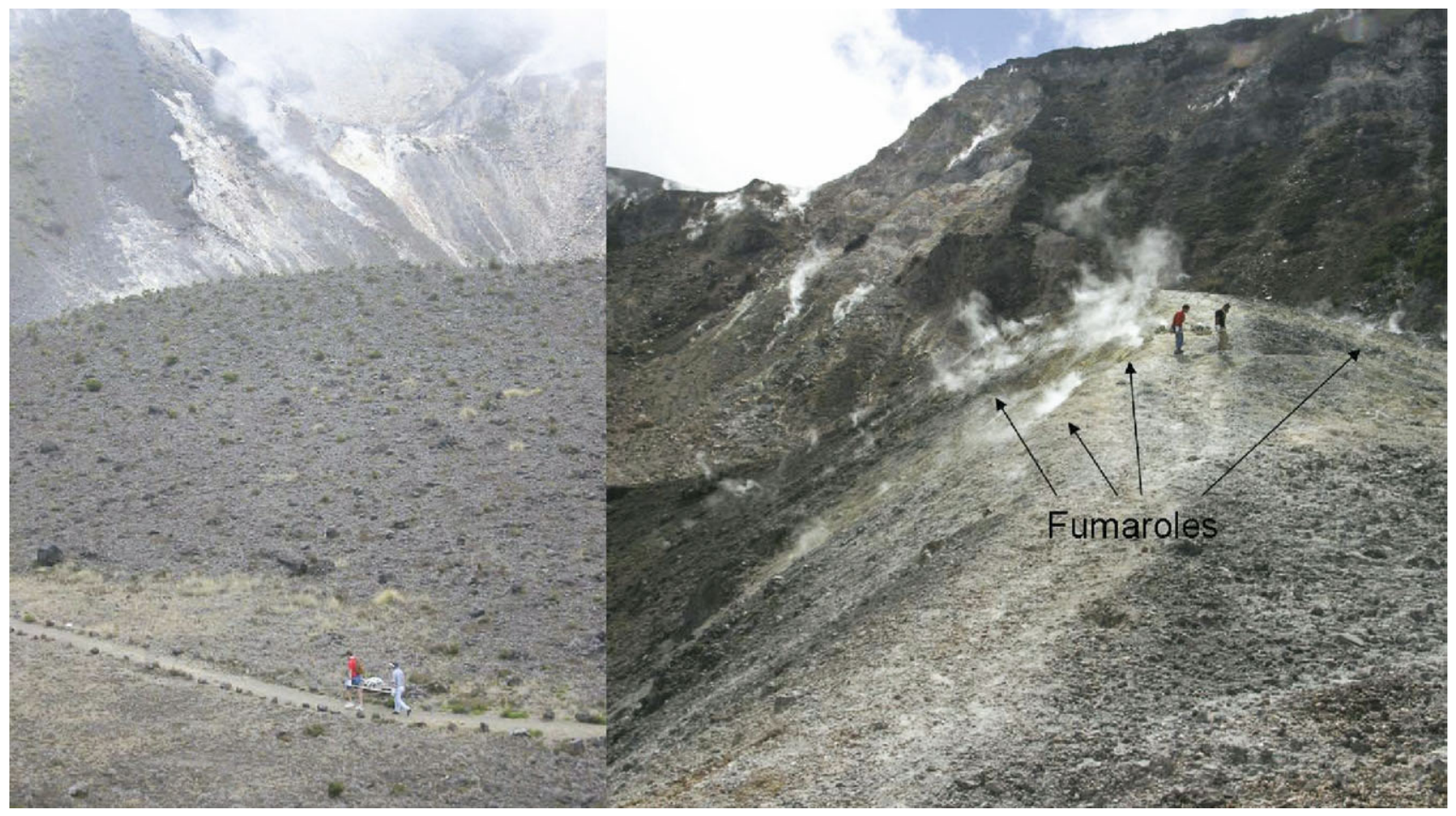

Figure 4. Left image: The system being hand-carried into Turrialba Volcano. System was handcarried to fumarolic area to be as close as possible, without major safety concerns, to the principal crater. Right image: Fumaroles were sampled at the central crater with inlet tight up to the GPS instrument. It was not possible to sample the principal crater due to terrain inaccessibility and high gas activity. 
indicate regions of highest concentration while green represent data points of lowest concentration. The data show that the emissions from the volcano are localized on the northwest side below the summit. This phenomenon is due to the prevailing winds of the region. The winds not only drive the gas plume west, but the shear effect causes the plume to drop closer to the ground. This is of significance because it brings the contamination closer to the ground, which increases the hazard potential in the local town of La Fortuna and surrounding areas. Although only $\mathrm{CO}_{2}$ data are shown, the plume also contains $\mathrm{SO}_{2}, \mathrm{H}_{2} \mathrm{~S}$, and other hazardous components that harm natural vegetation, area crops, and pose health risk to humans and wildlife.

Figure 3 shows the water concentration around the Irazu and Turrialba volcanoes. These volcanoes have high fumarole activity and are in close proximity to each other, $\sim 11 \mathrm{~km}$. The plumes from both volcanoes appear to drop below the caldera, as was the case with Arenal. Yet, here the two plumes seem to interact as they roll down the valley in a northwesterly heading. With the emissions consisting not only of water, but of $\mathrm{CO}_{2}, \mathrm{SO}_{2}, \mathrm{H}_{2} \mathrm{~S}$, and other toxins, this additive effect of the plumes could create very hazardous conditions for vegetation and population downwind.

\section{Hand-Carried Deployment}

The system was hand-carried (Figure 4) to an active section of the central crater of Turrialba volcano. It has three craters: the old, central, and principal crater. Although the central crater is not as active as the principal crater, which is inaccessible and located southwest of the central crater, it still provides representative data on the dynamics of Turrialba volcano. The $\mathrm{SO}_{2}$ data obtained within the central crater of Turrialba volcano are shown in Figure 5. This volcano poses a special interest because it recently has become increasingly active after having been dormant for the last 100 years. The data show the high concentration plume from a fumarolic area. The fumarole location is on the bottom portion of the plot (south). The winds pushed the plume north with little or no decrease in concentration until the plume diffused with the air layer surrounding the crater.

\section{Automobile Deployment}

The gas concentration data obtained while driving around Costa Rica's capital city of San Jose using AVEMS, are plotted in Figure 6. Concentration data
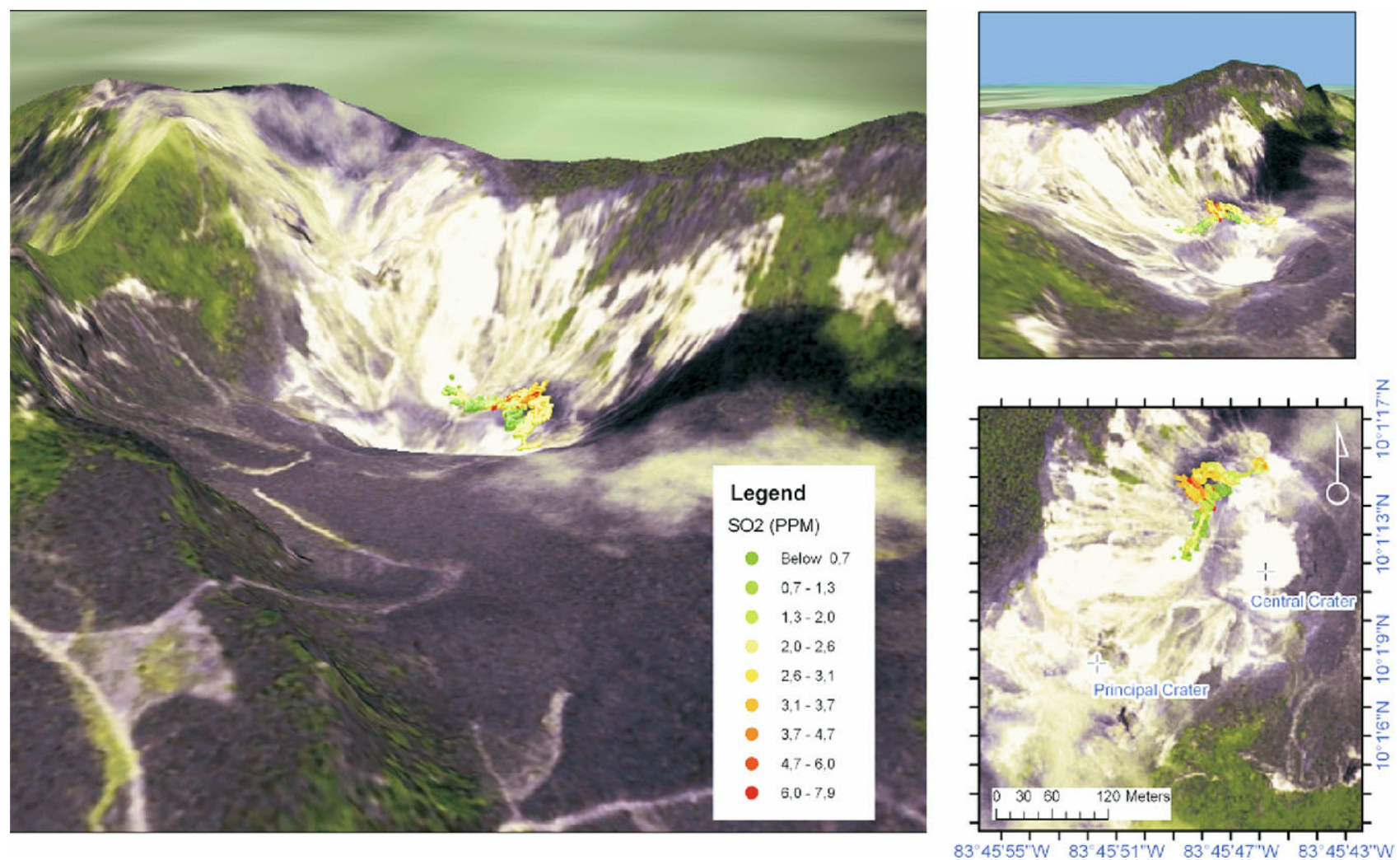

Figure 5. The sulfur dioxide fumarolic concentration profile of Turrialba volcano was measured by walking around with the sample intake line and GPS. The area selected was a newly formed fumarolic area at the rim of the central crater. Concentrations above 5 ppm were measured at different sites. Although the emissions are much more concentrated at the principal crater (above sampled area), the sites served to monitor the overall gas activity and geochemistry of Turrialba volcano. The intent is to place a permanent station at this site. 


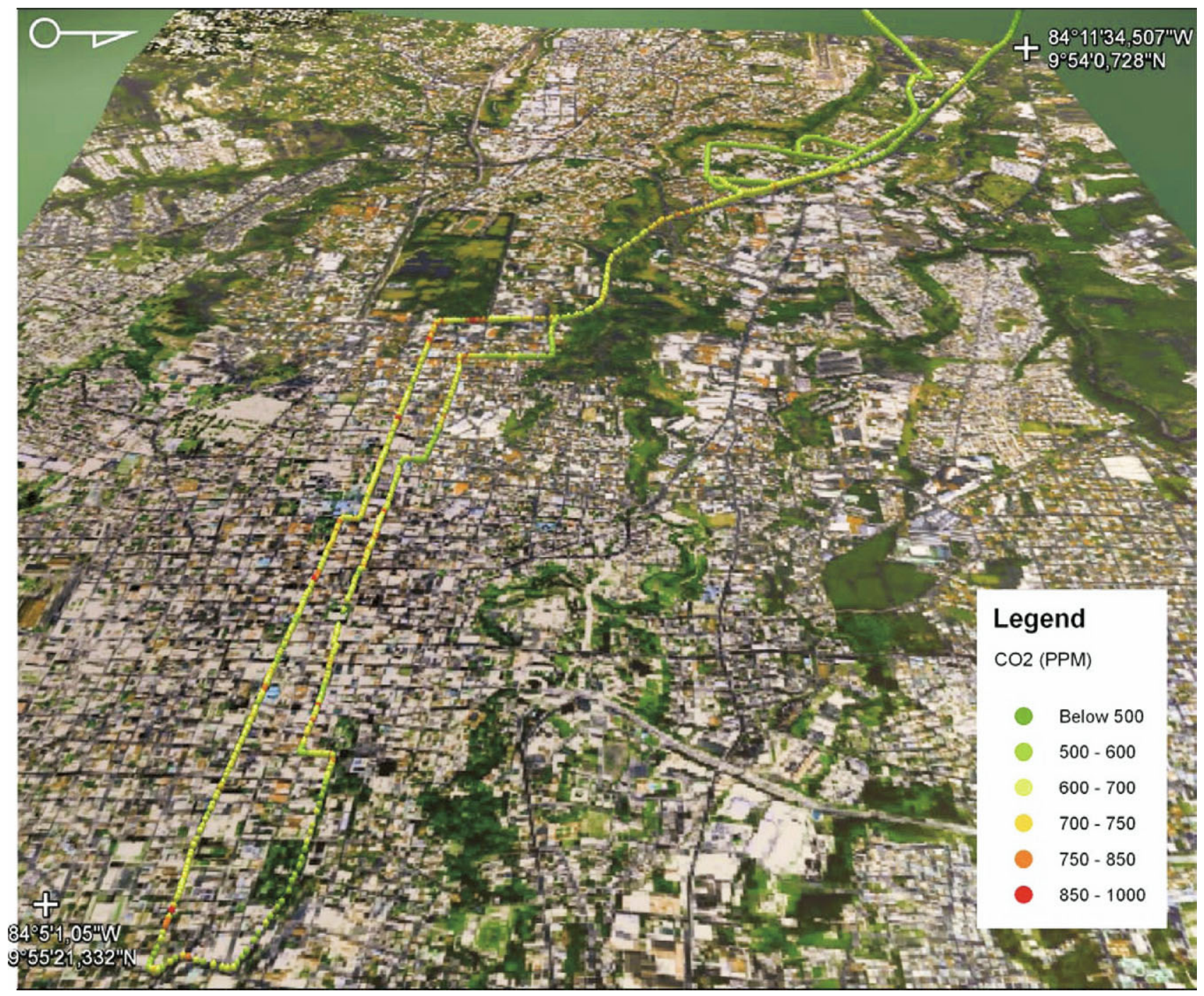

Figure 6. Collected while the mass spectrometer system was operating within an automobile, the $\mathrm{CO}_{2}$ concentration profile is shown leaving the International Airport (top right, not shown) and traveling along Costa Rica's primary highway (CR-1) toward downtown San Jose (lower left). The high concentration areas correspond to stop lights and slow moving traffic along the route.

are superimposed over topographic data and georeferenced natural color digital images forming a 3D map. The data show areas with high $\mathrm{CO}_{2}$ concentrations (red dots) in areas close to industrial locations and mainly in points along the highway system with high density of automobiles. Red dots coincide with red lights or before intersections with highly congested traffic.

The mapping with the on-board mass spectrometer provides a way to generate $2 \mathrm{D}$ contour maps. These maps could be used to recommend locations for fixed continuous monitoring points to the Department of Health and the Costa Rican universities, which are in charge of doing such regular monitoring. The data also provide air quality information in cities with no current volcanic activity, thus establishing baseline levels to be used in the event of volcanic events.

\section{Conclusions}

A versatile instrument was developed and deployed, which has successfully mapped gas concentrations around volcanoes, in an effort to better understand the evolution of the gases. The AVEMS system provided in-situ real-time data with mass range of 1-200 atomic mass units $(\mathrm{amu})$ and part per million ( $\mathrm{ppm}$ ) detection limits. The MS was flown on different aircraft and hand-carried within the crater of several volcanoes, further helping to understand the challenges required to integrate the instrument, deploy the system in the field, and collect data. The versatility of the instrument was further demonstrated by monitoring pollution levels around cities. The unit was transported by automobile while continuously monitoring the levels of pollution. All of these techniques provided useful 3D data to 
better visualize and model the gas dynamics in various environments.

Future work will be performed in two general areas, system improvement and application diversity. With an improved vacuum system, the instrument should stabilize in less than an hour, thus improving battery life and operational efficiency. Improvements to helium detection will be accomplished by modifications to the sample introduction subsystem. Significant upgrades to the software will allow near real time 3D plotting of data. The improved system will be used to monitor additional volcanoes. Other applications are sought, such as municipal gas monitoring, regulatory monitoring, emergency response, and agricultural characterization. The long-term objective is to demonstrate a small, autonomous, rugged, cost-effective system capable of monitoring gases on a continuous basis or on demand.

\section{Acknowledgments}

The authors thank ASRC team members, specifically Guy Naylor, for mechanical and logistical support, John Boelke for export control and other legal support, and David Floyd for embedded computer support. They thank the University of Costa Rica students and PRIAS-CENAT staff for their support during the mission, especially Kristel Heinrich, Laura Bogantes, Elian Conejo, and Dr. Pedro León. They also thank the vulcanologists Eliecer Duarte, Erick Fernandez, and Eduardo Malavassi from OVSICORI at UNA for their ongoing collaboration with the team. They thank Servicio de Vigilancia Aerea and Mr. Federico Chavarria K. for their support in not only lending the aircraft but in flying different aircraft during the CARTA-AVEMS campaigns. They acknowledge the Universidad de Costa Rica, CICANUM, CONARE, CRUSA Foundation, United States Embassy, CENAT, FUNCENAT, MICIT, DGAC, and the Engineering Directorate at Kennedy Space Center for their logistic and financial support.

\section{References}

1. Delmelle P.; J. Stix, J. Volcanic Gases. Encyclopedia of Volcanoes; Academic Press: San Diego, 2000; p. 803

2. Sutton, J.; Elias, T.; Hendley, J. W.; Stauffer, P. H. Volcanic Air Pollution-a Hazard in Hawaii. U.S. Geological Survey Fact Sheet 1997, 169,97

3. Sutton, A. J.; Elias, T.; Navarette, R. Volcanic Gas Emissions and Their Effects on Ambient Air Character at Kilauea volcano, Hawaii. U.S. Geological Survey Open-File Report 1994, 94, 569.

4. Sutton, A. J.; Elias, T. Volcanic Gases Create Air Pollution on the Island of Hawaii. Earthquakes and Volcanoes 1993, 24(4), 178.

5. Symonds, R. B.; Rose, W. I.; Bluth, G. J. S.; Gerlach, T. M. Volcanic-Gas Studies: Methods, Results, and Applications. Volatiles in Magmas. Mineralogical Society of America Reviews in Mineralogy 1994, 30, 1.

6. Williams, S. N.; Sano, Y.; Wakita, H. Helium-3 Emission from Nevado del Ruiz volcano, Colombia. Geophys. Res. Lett. 1987, 14, 1035.

7. Grant, W. B.; Browell, E.V.; Fishman, J.; Brackett, V. G.; Veiga, R. E.; Nganga, D.; Minga, A.; Cros, B.; Butler, C. F.; Fenn, M. A.; Long, C. S.; Stowe, L. L.; Aerosol-Associated Changes in Tropical Stratospheric Ozone Following the Eruption of Mount Pinatubo. J. Geophys. Res. 1994, 99, 8197.

8. Sutton, A. G.; McGee, K. A.; Casadevall, T. J.; Stokes, J. B. Fundamental Volcanic Gas Study Techniques: An Integrated Approach to Monitoring: Monitoring Volcanoes: Techniques and Strategies Used by the Staff of the Cascades Volcano Observatory, 1980-1990. USGS Bulletin No. 1966 1992, 181.

9. Diaz, J. A.; Giese, C. F.; Gentry, W. R. Mass Spectrometry for in-Situ Volcanic Gas Monitoring. Trends Anal. Chem. 2002, 21(8), 498.

10. Sano, Y.; Hiroshi, H.; Giggenbach, W. F. Island Arc Tectonics of New Zealand Manifested in Helium Isotope Ratios. Geochemica Cosmochimica Acta 1987, 51(7), 1855.

11. Arkin, C. R.; Griffin, T. P.; Diaz, J. A.; Follistein, D. W.; Curley, C. H.; Floyd, D. P.; Naylor, G. R.; Haskell, W. D.; Blalock, M.; Adams F. W. A Small Mass Spectrometer System for in Situ Gas Analysis. Trends Anal. Chem. 2004, 23(4), 32

12. Diaz, J. A.; Giese, C. F.; Gentry, W. R. Portable Double Focusing Mass Spectrometer System for Field Gas Monitoring. Field Anal. Chem. Technol. 2001, 5(3), 156.

13. Toutain, J. P.; Baubron, J. C.; Le Bronec, J.; Allard, P.; Briole, P.; Marty, B.; Miele, G.; Tedesco, D.; Luongo, G.; Continuous Monitoring of Distal Gas Emanations at Vulcano, southern Italy. Bull. Volcanol. 1992, 54, 147.

14. Anderson, G. L.; Hadden, D. M. The Gas Monitoring Handbook. Avocet Press: Pearl River, NY, 1999, p. 128.

15. Boyes, W. Chemical Analysis: Gas Analysis. Instrumentation Reference Book, 3rd ed; Butterworth-Heinemann: 2002.

16. Farr, T. G.; Rosen, P. A.; Caro, E.; Crippen, R.; Duren, R.; Hensley, S.; Kobrick, M.; Paller, M.; Rodriguez, E.; Roth, L.; Seal, D.; Shaffer, S.; Shimada, J.; Umland, J.; Werner, M.; Oskin, M.; Burbank, D.; Alsdorf, D.; Okford, UK, The Shuttle Radar Topography Mission, (SRTM). Rev. Geophys. 2007, 45, RG2004. 